\title{
Effect of Cinnamaldehyde on Hyphal Growth of C. albicans Under Various Treatment Conditions
}

\author{
Yuuki Taguchi ${ }^{1}$, Yayoi Hasumi ${ }^{2}$, Kazumi Hayama ${ }^{2}$, Ryo Arai ${ }^{1}$, Yayoi Nishiyama ${ }^{2}$, \\ Shigeru Abe ${ }^{2}$ \\ ${ }^{1}$ Research and Product Development Division, S\&B Foods Inc. \\ ${ }^{2}$ Teikyo University Research Institute of Medical Mycology
}

\begin{abstract}
This study investigated the effects of cinnamaldehyde in combatting the hyphal growth of Candida albicans under varying concentrations, treatment times, and temperatures to determine the potential benefits of applying this substance to anti-Candida foods or gargles. From the results of pretreatment with cinnamaldehyde against Candida hyphae, we found that its inhibitory activity seemed to be strengthened in parallel with prolonged pretreatment time and a rise in temperature, and that pretreatment of $2,000 \mu \mathrm{g} / \mathrm{m} /$ for only 1 minute significantly inhibited the hyphal growth of $C$. albicans. We also demonstrated by XTT assay that pretreatment with cinnamaldehyde affected the metabolic activity of Candida hyphal cells. These findings suggest that a warm drink or mouthwash containing cinnamaldehyde might be a candidate as a prophylactic or therapeutic tool against oral Candida infection.
\end{abstract}

Key words : Candida albicans, cinnamaldehyde, hyphal growth, crystal violet staining assay, XTT assay

\section{Introduction}

Candida albicans, a dimorphic fungus, is a member of the oral microbial flora in healthy human individuals, frequently and opportunistically growing excessively and becoming the causative agent of oral candidiasis ${ }^{1,2)}$. The hyphal form of $C$. albicans can invade human mucosal tissue, and exert its pathogenicity ${ }^{3,4)}$. Pathogenic symptoms of oral candidiasis accompanied by severe inflammation aggravate the quality of life of immunosuppressed individuals and elderly people $^{5,6)}$.

Since spices and herbs have traditionally been used as anti-microbiological tools in daily life throughout the world, we and our colleagues have investigated their anti-Candida activity to develop new therapies ${ }^{7-9)}$.

Previously, we reported that a cassia (Cinnamomum cassia) preparation inhibited hyphal growth of $C$. albicans and exerted a therapeutic effect on a murine oral candidiasis model ${ }^{9,10)}$. Additionally, the results of gas chromatography / mass spectrometry (GC/MS) analysis suggested that cinnamaldehyde is the major component of the essential oil of cassia, and that it was responsible for the inhibitory activity in the cassia preparation ${ }^{9}$.

In the present study, we examined the effect of cinnamaldehyde against hyphal growth of $C$. albicans under varying treatment times (from 1 to 60 minutes) and temperature conditions when applied to preparation of an anti-Candida food or gargle. We speculate that if an herbal material such as cassia preparation can be developed as a candy, drink, or gargle with a clinically therapeutic function against oral candidiasis, its active principle would need to display antifungal activity by limited term interaction with $C$. albicans. We also examined the metabolic activity of Candida cells after treatment with cinnamaldehyde. 
Here we report that the inhibitory activity of cinnamaldehyde against Candida hyphal growth tends to be strengthened by prolonged pretreatment time and higher temperature condition, and that even a 1 minute pretreatment with this substance exerts an inhibitory activity against Candida cells and affects their metabolic activity.

\section{Materials and Methods}

\section{C. albicans strain}

C. albicans TIMM1768 was used in this study. The strain was grown on Sabouraud dextrose agar plate for $18 \mathrm{~h}$ at $37^{\circ} \mathrm{C}$. Cells were harvested with a microspatula and suspended in RPMI1640 medium containing $2.5 \%$ fetal calf serum (RP medium). The suspension of $C$. albicans was used as the inoculum for all subsequent experiments ${ }^{9,11)}$.

\section{Preparation of cinnamaldehyde}

Cinnamaldehyde was purchased from Wako Pure Chemical Industries, Ltd. (Osaka, Japan) and dissolved in dimethylsulfoxide (DMSO) at 10\% (w/w) prior to dilution with RP medium as described previously ${ }^{8,9)}$

\section{Measurement of activities of cinnamaldehyde against Candida hyphal growth}

Inhibitory activity of cinnamaldehyde against Candida hyphal growth was assessed by a crystal violet (CV) staining method as described previously $^{11-13)}$. In brief, Candida cells were seeded in a 96-well flat bottom microplate at $5 \times 10^{3}$ cells $/ \mathrm{ml}$ in a volume of $200 \mu \mathrm{l}$ RP medium and preincubated for 3 hours at $37^{\circ} \mathrm{C}$ in a $5 \% \mathrm{CO}_{2}$ atmosphere. After the microscopic observation of Candida growth, the medium was aspirated, and then $200 \mu l$ of the cinnamaldehyde preparation was loaded onto the microplate and incubated at $37,40,42.5$, and $45^{\circ} \mathrm{C}$ for $1,20,40$, and 60 minutes. The conditions of pretreatment time and temperature were established on the assumption that cinnamaldehyde is used in gargles and foods such as candy, chewing gum, and spiced tea ${ }^{10,14)}$. (Since it is reported that humans perceive heat stimuli $\left(>=46^{\circ} \mathrm{C}\right)$ as unpleasant contact, temperature conditions were set at less than $45^{\circ} \mathrm{C}^{15-17)}$.) The sample solution was removed and each well was washed twice with RP medium. Then $200 \mu$ l of RP medium was loaded onto the microplate and incubated for 14 to 15 hours at $37^{\circ} \mathrm{C}$ in a $5 \% \mathrm{CO}_{2}$ atmosphere.

The medium in the wells was discarded by inverting the microplate. Hyphal cells of $C$. albicans which adhered to the bottom of the wells were sterilized by treatment with $70 \%$ ethanol and stained with $0.01 \% \mathrm{CV}$. The microplate was washed with water and dried, and then $150 \mu l$ of isopropanol containing $0.04 \mathrm{~N} \mathrm{HCl}$ and $50 \mu l$ of $0.25 \%$ sodium dodecyl sulfate was added to the wells and mixed. The absorbance at $620 \mathrm{~nm}$ of quadruplicate samples was measured spectrophotometrically.

\section{Metabolic activity measurement of Candida cells treated with cinnamaldehyde}

Metabolic activity of Candida cells incubated for 1, 20, 60 minutes with varying concentrations of cinnamaldehyde was measured by XTT [2,3-bis (2-methoxy-4-nitro-5-sulfophenyl)-2H-tetrazolium-5-carboxanilide sodium salt] assay as described previously ${ }^{18-22)}$. Briefly, Candida cells prepared at $5 \times 10^{5} \mathrm{cells} / \mathrm{m} /$ in RP medium were treated with cinnamaldehyde preparation using the same method as in the crystal violet assay. Two hundred $\mu /$ of XTT solution was added and incubated at $37^{\circ} \mathrm{C}$ for 2.5 hours. The plate was centrifuged $(1,500 \mathrm{rpm}, 1 \mathrm{~min})$ and $100 \mu /$ of supernatant in each well was placed in a new well. The absorbance at $450 \mathrm{~nm}$ of quadruplicate samples was measured spectrophotometrically.

\section{Results}

Inhibitory activities of cinnamaldehyde against $C$. albicans hyphal growth under the various experimental conditions

Inhibitory activities of cinnamaldehyde against growing hyphae of $C$. albicans after treatment for 20,40 , and 60 minutes at $37,40,42.5,45^{\circ} \mathrm{C}$ were examined by $\mathrm{CV}$ staining method, and the results are shown in Table 1.

Inhibitory activity of each preparation was compared by $\mathrm{IC}_{50}$, the concentration of cinnamaldehyde which reduced growth of $C$. albicans by $50 \%$ for the non-treatment group (control). $\mathrm{IC}_{50}$ of the 20 minute pretreatment at $37^{\circ} \mathrm{C}$ was $320-800$ $\mu \mathrm{g} / \mathrm{ml}$. When pretreatment time was prolonged to 40 or 60 minutes at the same temperature, $I C_{50}$ for both periods was decreased to $128-320 \mu \mathrm{g} / \mathrm{m} /$. It was also shown that $\mathrm{IC}_{50}(128-320 \mu \mathrm{g} / \mathrm{m} /)$ of the 20 minute pretreatment at $40^{\circ} \mathrm{C}$ was lower than $\mathrm{IC}_{50}$ 
Table 1. Inhibitory acitivity of cinnamaldehyde on Candida hyphal growth under the conditions of varying temperature and time

\begin{tabular}{ccc}
\hline $\begin{array}{c}\text { Treatment } \\
\text { temperature }\left({ }^{\circ} \mathrm{C}\right)\end{array}$ & Treatment time $(\mathrm{min})$ & $\begin{array}{c}\mathrm{IC}_{50} \text { (hyphal growth) } \\
\text { (concentration: } \mu \mathrm{g} / \mathrm{m} /)\end{array}$ \\
\hline 37 & 20 & $320-800$ \\
& 40 & $128-320$ \\
40 & 60 & $128-320$ \\
\hline \multirow{2}{*}{40} & 20 & $128-320$ \\
& 40 & $128-320$ \\
& 60 & $51.2-128$ \\
\hline 45 & 20 & $128-320$ \\
& 40 & $128-320$ \\
& 60 & $51.2-128$ \\
\hline & 20 & $128-320$ \\
& 40 & $51.2-128$ \\
& 60 & $51.2-128$ \\
\hline
\end{tabular}

Inhibitory activity of cinnamaldehyde against Candida hyphal growth was measured by crystal violet (CV) staining method as described in Materials and Methods.

Each group was treated with cinnamaldehyde for 20,40 , and 60 minutes at 37 , $40,42.5$ and $45^{\circ} \mathrm{C}$, respectively.

The concentration of $50 \%$ inhibition against Candida hyphal growth is indicated as the range between two concentrations.

Table 2. Inhibitory acitivity of 1 minute pretreatment with cinnamaldehyde against Candida hyphal growth

\begin{tabular}{ccc}
\hline Treatment & \multicolumn{2}{c}{ Relative values of Candida mycelia (\%) } \\
\cline { 2 - 3 } temperature $\left({ }^{\circ} \mathrm{C}\right)$ & $\begin{array}{c}2,000 \mu \mathrm{g} / \mathrm{m} / \text { of } \\
\text { cinnamaldehyde }\end{array}$ & $\begin{array}{c}800 \mu \mathrm{g} / \mathrm{m} / \text { of } \\
\text { cinnamaldehyde }\end{array}$ \\
\hline 37 & 6.26 & 100 \\
40 & 5.61 & 99.5 \\
42.5 & 2.92 & 77.3 \\
45 & 2.83 & 68.1 \\
\hline
\end{tabular}

Inhibitory activityof cinnamaldehyde for Candida hyphal growth was measured by CV staining method as described in Materials and Methods.

Each group was treated with 2,000 or $800 \mu \mathrm{g} / \mathrm{m} /$ of cinnamaldehyde for 1 minute at $37,40,42.5$ and $45^{\circ} \mathrm{C}$, respectively.

Results are shown as the relative value of Candida hyphal growth under each pretreatment condition for non-pretreatment group (100\%).

$(320-800 \mu \mathrm{g} / \mathrm{m} /)$ at $37^{\circ} \mathrm{C}$. In the 60 minute pretreatment, $\mathrm{IC}_{50}(51.2-128 \mu \mathrm{g} / \mathrm{m} /)$ at $40^{\circ} \mathrm{C}$ was lower than $\mathrm{IC}_{50}(128-320 \mu \mathrm{g} / \mathrm{m} /)$ of the same pretreatment time at $37^{\circ} \mathrm{C} .1 \mathrm{C}_{50}$ at 42.5 and $45^{\circ} \mathrm{C}$ was at almost the same level as that of the 40 minute pretreatment, but that at $45^{\circ} \mathrm{C}(51.2-128 \mu \mathrm{g} / \mathrm{m} /)$ was the same as $I C_{50}$ of the 60 minute pretreatment at 42.5 and $45^{\circ} \mathrm{C}$. These results show that the inhibitory activity of cinnamaldehyde against Candida mycelial growth tends to be enhanced by prolonged pretreatment time and rising temperature.

Using the CV staining method (Table 2), we also evaluated the inhibitory activity of cinnamaldehyde against Candida hyphae for 1 minute to 
Table 3. Metabolic activity of Candida hyphal cells treated with cinnamaldehyde under the conditions of varying temperature and time

\begin{tabular}{|c|c|c|c|c|c|c|}
\hline \multirow{2}{*}{$\begin{array}{c}\text { Treatment } \\
\text { temperature } \\
\left({ }^{\circ} \mathrm{C}\right)\end{array}$} & \multirow{2}{*}{$\begin{array}{l}\text { Treatment } \\
\text { time } \\
\text { (min) }\end{array}$} & \multicolumn{5}{|c|}{ Metabolic activity of $C$. albicans (\%) } \\
\hline & & $\begin{array}{c}2,000 \mu \mathrm{g} / \mathrm{m} / \text { of } \\
\text { cinnamaldehyde }\end{array}$ & $\begin{array}{c}800 \mu \mathrm{g} / \mathrm{m} / \text { of } \\
\text { cinnamaldehyde }\end{array}$ & $\begin{array}{c}320 \mu \mathrm{g} / \mathrm{m} / \text { of } \\
\text { cinnamaldehyde }\end{array}$ & $\begin{array}{c}128 \mu \mathrm{g} / \mathrm{m} / \text { of } \\
\text { cinnamaldehyde }\end{array}$ & control \\
\hline \multirow{3}{*}{37} & 1 & $65.7 \pm 0.11$ & $87.7 \pm 3.45$ & $85.2 \pm 4.00$ & $95.1 \pm 5.07$ & 100 \\
\hline & 20 & $23.2 \pm 4.60$ & $27.1 \pm 4.19$ & $35.6 \pm 4.87$ & $72.1 \pm 4.64$ & 100 \\
\hline & 60 & $10.2 \pm 0.76$ & $11.5 \pm 0.59$ & $17.6 \pm 0.40$ & $44.6 \pm 3.73$ & 100 \\
\hline \multirow{3}{*}{45} & 1 & $56.0 \pm 3.45^{\star}$ & $74.5 \pm 7.90^{*}$ & $84.8 \pm 1.07$ & $87.5 \pm 4.94$ & 100 \\
\hline & 20 & $12.4 \pm 0.86^{*}$ & $15.0 \pm 2.13^{*}$ & $19.8 \pm 2.12^{*}$ & $66.7 \pm 6.30$ & 100 \\
\hline & 60 & $6.64 \pm 0.41^{*}$ & $7.40 \pm 0.41^{*}$ & $8.10 \pm 0.44^{*}$ & $27.1 \pm 1.83^{*}$ & 100 \\
\hline
\end{tabular}

Metabolic activity of Candida hyphal cells was measured by XTT assay as described in Materials and Methods. Each group was treated with cinnamaldehyde for 1,20 , and 60 minutes at $37^{\circ} \mathrm{C}$ and $45^{\circ} \mathrm{C}$, respectively. Metabolic activity is shown as the relative value of each pretreatment group to the values of non-pretreatment group (control).

The values at $37^{\circ} \mathrm{C}$ and $45^{\circ} \mathrm{C}$ were compared by corresponding values of each treatment time and dose condition, respectively.

$P$ values of $<0.05$ were considered as significant. $\left(^{*}: p\right.$ values of $<0.05$ )

determine its efficacy using a pretreatment time shorter than 20 minutes.

Since 1 minute pretreatment with $800 \mu \mathrm{g} / \mathrm{m} /$ of cinnamaldehyde at $37^{\circ} \mathrm{C}$ did not inhibit hyphal growth significantly in preliminary experiments, we examined its inhibitory activity at the concentrations of 800 and $2,000 \mu \mathrm{g} / \mathrm{m} /$ at $37,40,42.5,45^{\circ} \mathrm{C}$. The inhibitory activity of 1 minute pretreatment against Candida hyphal growth was shown as the relative growth of Candida hyphae of each pretreatment group to the non-pretreatment group (control). While the pretreatment with $800 \mu \mathrm{g} / \mathrm{m} /$ cinnamaldehyde for 1 minute at $37^{\circ} \mathrm{C}$ did not inhibit the hyphal growth of $C$. albicans, pretreatment with the same dose at $45^{\circ} \mathrm{C}$ lowered the growth of these hyphae to $68.1 \%$.

With $2,000 \mu \mathrm{g} / \mathrm{m} /$ pretreatment, Candida hyphal growth was lowered to $6.26 \%$ at $37^{\circ} \mathrm{C}$; further, growth of these hyphae pretreated with the same amount of material at $45^{\circ} \mathrm{C}$ was inhibited to $2.83 \%$.

These data indicate not only that the inhibitory activity of cinnamaldehyde seemed to be strengthened by prolonged pretreatment time and rising temperature, but also that $2,000 \mu \mathrm{g} / \mathrm{m} /$ of this substance strongly inhibited hyphal growth of $C$. albicans, when preincubated with it even for 1 minute.

\section{Metabolic activity of Candida cells treated with cinnamaldehyde}

Effects of pretreatment with cinnamaldehyde on the metabolic activity of $C$. albicans hyphal cells were also examined by XTT assay.

Table 3 shows that metabolic activity of these cells decreased from $95.1 \%(128 \mu \mathrm{g} / \mathrm{m} /, 1$ minute, $\left.37^{\circ} \mathrm{C}\right)$ to $6.64 \%\left(2,000 \mu \mathrm{g} / \mathrm{m} /, 60\right.$ minutes, $\left.45^{\circ} \mathrm{C}\right)$, and tended to decrease in a time- or dose-dependent manner at $37^{\circ} \mathrm{C}$ and $45^{\circ} \mathrm{C}$. Comparing the metabolic activity at 37 and $45^{\circ} \mathrm{C}$, the hyphae treated at $45^{\circ} \mathrm{C}$ seemed to be lower than the corresponding values at $37^{\circ} \mathrm{C}$.

The results also show that metabolic activity of Candida cells treated with $2000 \mu \mathrm{g} / \mathrm{m} /$ cinnamaldehyde for 1 minute decreased to $65.7 \%$ at $37^{\circ} \mathrm{C}$, and the hyphal growth after 1 minute pretreatment at $45^{\circ} \mathrm{C}(56.0 \%)$ was lower than the corresponding value at $37^{\circ} \mathrm{C}$. The results of XTT assay demonstrate that even 1 minute pretreatment of cinnamaldehyde lowered the metabolic activity of Candida albicans and this effect seemed to be stronger at $45^{\circ} \mathrm{C}$.

\section{Discussion}

We examined the inhibitory activity of cinnamaldehyde pretreatment against Candida hyphal growth at varying times and temperatures, since 
this material has been a part of the regular diet in cooked foods and teas in many countries throughout the ages ${ }^{23)}$.

In this study, we demonstrated that pretreatment of C. albicans with cinnamaldehyde $(2,000$ $\mu \mathrm{g} / \mathrm{m} /$ ) for just 1 minute, exerted an inhibitory activity on its hyphal growth. The dose of 2,000 $\mu \mathrm{g} / \mathrm{m} /$ seems somewhat higher than that usually intaken in daily life, but this concentration has been reported as safe to be consumed ${ }^{9,10,24)}$.

The results of CV staining and XTT assay showed that the inhibitory activity of cinnamaldehyde seemed to be strengthened in parallel with a rise in temperature in warm tea which is not rejected for its unpleasant temperature effect ${ }^{16,17)}$. In the previous study, we reported that oral administration of $50 \mu \mathrm{l}$ of a solution with 19.5 $\mathrm{mg} / \mathrm{m} /$ of cinnamaldehyde or cassia which contained $19.5 \mathrm{mg} / \mathrm{m} /$ of cinnamaldehyde exerted a therapeutic activity against murine oral candidiasis $^{9,11}$. This effective concentration is about 10 times that of the $2,000 \mu \mathrm{g} / \mathrm{m} /$ effective in vitro in the pretreatment assay. We do not believe that this difference is strange because oral administration would be followed by diffusion in the oral cavity ${ }^{7,9,10)}$. It is also our opinion that the temperature dependence on cinnamaldehyde effects in vitro suggest that oral intake of a hot food or beverage containing this substance such as spiced tea in daily life may be one of the more effective methods of inhibiting Candida hyphal growth.

It now appears to us necessary that in order to realize the successful application of cinnamaldehyde to combat human oral candidiasis, we must examine other optimal conditions, such as optimal $\mathrm{pH}$, physical condition, potentiation of the effects of cinnamaldehyde in combination with other food agents and details of interaction between cinnamaldehyde and Candida albicans ${ }^{10,23,25)}$. It is our hope that these studies will facilitate development of the application of spices and herbs in daily use to prevent and improve the problem of oral candidiasis in elderly and immunocompromised patients.

\section{References}

1) Odds FC: A Review and Bibliography. Candida and Candidosis: 4-129, Bailliere Tindale, London, 1988.

2) Dongari-Bagtzoglou A, Dwivedi $P$, loannidou $E$, Shaqman M, Hull D and Burleson J: Oral Candida infection and colonization in solid organ transplant recipients. Oral Microbiol Immunol 24: 249-254, 2009.

3) Hornby JM, Jensen EC, Lisec AD, Tasto JJ, Jahnke B, Shoemaker R, Dussault P, Nickerson $\mathrm{KW}$ : Quorum sensing in the dimorphic fungus Candida albicans is mediated by farnesol. Appl Environ Microbiol 67: 2982-2992, 2001

4) Felk $A$, Kretschmar $M$, Albrecht $A$, Schaller $M$, Beinhauer S, Nichterlein T, Sanglard D, Korting HC, Schäfer W, Hube B: Candida albicans hyphal formation and the expression of the Efg1regulated proteinases Sap4 to Sap6 are required for the invasion of parenchymal organs. Infect Immun. 70: 3689-700, 2002.

5) Bodey GP: Pathogenesis, Diagnosis and Treatment. Candidiasis 2nd edition: Raven Press, New York, 1993.

6) Sullivan D, Coleman D: Candida dubliniensis: characteristics and identification. J Clin Microbiol 36: 329-334, 1998.

7) Taguchi $Y$, Komiya M, Ishibashi H, Inoue $S$, Yamaguchi $\mathrm{H}$, Arai R, Abe S: Inhibition of mycelial growth of Candida albicans by spices and herbs in vitro and effects of their oral administration on intestinal colonization of Candida albicans in mice. Pharmacometrics 64: 53-57, 2003.

8) Taguchi $Y$, Ishibashi $H$, Takizawa $T$, Inoue $S$, Yamaguchi H, Abe S: Protection of oral candidiasis in mice by oral or intragastric administration of herbal food, clove (Syzygium aromaticum). Jpn J Med Mycol 46: 27-33, 2005.

9) Taguchi Y, Takizawa T, Ishibashi H, Sagawa T, Arai $\mathrm{R}$, Inoue S, Yamaguchi H, Abe S: Therapeutic effects on murine oral candidiasis by oral administration of cassia (Cinnamomum cassia) preparation. Jpn J Med Mycol 51: 13-21, 2010.

10) Taguchi $Y$, Hayama K, Okada M, Sagawa T, Arai R, Abe S: Therapeutic effects of cinnamaldehyde and potentiation of its efficacy in combination with methylcellulose on murine oral candidiasis. Med Mycol J 52: 145-52, 2011.

11) Hayama K, Ishibashi $H$, Kitadate $K$, Yamazaki M, Abe S: Therapeutic effect of oligonol, a lowmolecular polyphenol formulation derived from lychee fruits on murine oral candidiasis. Jpn J Med Mycol 51: 137-142, 2010.

12) Abe S, Satoh T, Tokuda $Y$, Tansho $S$, Yamaguchi $H$ : A rapid colorimetric assay for determination of leukocyte-mediated inhibition of mycelial growth of Candida albicans. Microbiol Immunol 38: 385-388, 1994.

13) Inoue S, Takahashi M, Abe S: Inhibitory activity of hydrosols, herbal teas and related essential oils against filament formation and the growth of Candida albicans. Jpn J Med Mycol 50: 243-251, 2009.

14) Zhu M, Carvalho R, Scher A, Wu CD: Short-term germ-killing effect of sugar-sweetened cinnamon chewing gum on salivary anaerobes associated 
with halitosis. J Clin Dent 22: 23-6, 2011.

15) Riedy CA, Milgrom P, Ly KA, Rothen M, Mueller G, Hagstrom MK, Tolentino E, Zhou L, Roberts MC: A surrogate method for comparison analysis of salivary concentrations of xylitol-containing products. BMC Oral Health 8: 5, 2008. (on line article)

16) Tran TD, Wang $H$, Tandon $A$, Hernandez-Garcia $L$, Casey KL: Temporal summation of heat pain in humans: Evidence supporting thalamocortical modulation. Pain 150: 93-102, 2010.

17) Moulton EA, Elman I, Pendse G, Schmahmann J, Becerra L, Borsook D: Aversion-related circuitry in the cerebellum: responses to noxious heat and unpleasant images. J Neurosci 31: 3795-804, 2011

18) Meshulam T, Levitz SM, Christin L, Diamond RD: A simplified new assay for assessment of fungal cell damage with the tetrazolium dye, $(2,3)$-bis(2-methoxy-4-nitro-5-sulphenyl) - (2H) -tetrazolium-5-carboxanilide (XTT). J Infect Dis 172 : 1153-1156, 1995.

19) Meletiadis J, Mouton JW, Meis JF, Bouman BA, Donnelly JP, Verweij PE; EUROFUNG Network: colorimetric assay for antifungal susceptibility testing of Aspergillus species. J Clin Microbiol 39: 3402-3408, 2001.

20) Ahmed $A O$, van de Sande WW, van Vianen W, van Belkum A, Fahal AH, Verbrugh HA, BakkerWoudenberg IA: In vitro susceptibilities of Madurella mycetomatis to itraconazole and amphotericin B assessed by a modified NCCLS method and a viability-based 2, 3-Bis (2-methoxy-4-nitro-5-sulfophenyl) -5- [(phenylamino)
carbonyl]-2H-tetrazolium hydroxide (XTT) assay. Antimicrob Agents Chemother 48: 2742-2746, 2004.

21) van de Sande WW, Luijendijk $A$, Ahmed $A O$, Bakker-Woudenberg IA, van Belkum A. Testing of the in vitro susceptibilities of Madurella mycetomatis to six antifungal agents by using the Sensititre system in comparison with a viabilitybased 2,3-bis (2-methoxy-4-nitro- 5-sulfophenyl) -5-[(phenylamino) carbonyl]-2H-tetrazolium hydroxide (XTT) assay and a modified NCCLS method. Antimicrob Agents Chemother 49: 1364-1368, 2005.

22) Knight SA, Dancis A: Reduction of 2, 3-bis (2-methoxy-4-nitro-5-sulfophenyl) -2H-tetrazolium-5-carboxanilide inner salt (XTT) is dependent on CaFRE10 ferric reductase for Candida albicans grown in unbuffered media. Microbiology 152: 2301-2308, 2006.

23) Sardi JC, Duque C, Mariano FS, Peixoto IT, Höfling JF, Gonçalves RB: Candida spp. in periodontal disease: a brief review. J Oral Sci 52: 177-185, 2010.

24) Ali SM, Khan AA, Ahmed I, Musaddia M, Ahmed KS, Polasa H, Rao LV, Habibullah CM, Sechi LA, Ahmed N: Antimicrobial activities of eugenol and cinnamaldehyde against the human gastric pathogen Helicobacter pylori. Ann Clin Microbiol Antimicrob 4: 2005. (doi: 10. 1186/1476-0711-4-20)

25) Jabra-Rizk MA, Falkler WA Jr, Merz WG, Kelley ال ال, Baqui AA, Meiller TF: Coaggregation of Candida dubliniensis with Fusobacterium nucleatum. J Clin Microbiol 37: 1464-1468, 1999. 